CARDOSO, O. O. O leite materno e as relações existentes entre as concentrações de metais pesados de diferentes matrizes ambientais. 2010. 195 p. Tese (Doutorado) - Escola de Enfermagem de Ribeirão Preto, Universidade de São Paulo, Ribeirão Preto, 2010.

\title{
ERRATA
}

\section{Folha 91}

Onde se lê:

\subsection{OBJETIVOS ESPECÍFICOS}

Reconhecer os indicadores da política do aleitamento materno do município de Conceição das Alagoas, MG, Brasil;

Identificar fatores sócio-ambientais que podem interferir na qualidade do leite materno;

Avaliar as concentrações e as correlações dos metais pesados $(\mathrm{Cd}, \mathrm{Cr}, \mathrm{Cu}$, $\mathrm{Fe}, \mathrm{Hg}, \mathrm{Mn}, \mathrm{Ni}, \mathrm{Pb}, \mathrm{Sn}, \mathrm{Zn}$ ) no colostro, leite de transição e leite maduro das lactantes de Conceição das Alagoas;

\section{Leia-se:}

\subsection{OBJETIVOS ESPECÍFICOS}

Avaliar as concentrações e as correlações dos metais pesados $(\mathrm{Cd}, \mathrm{Cr}, \mathrm{Cu}$, $\mathrm{Fe}, \mathrm{Hg}, \mathrm{Mn}, \mathrm{Ni}, \mathrm{Pb}, \mathrm{Sn}, \mathrm{Zn}$ ) no colostro, leite de transição e leite maduro das lactantes de Conceição das Alagoas;

\section{Folha 142}

Onde se lê:

\begin{tabular}{ccccccccccc}
\hline Solo & $\mathbf{C r}$ & $\mathbf{Z n}$ & $\mathbf{C u}$ & $\mathbf{H g}$ & $\mathbf{N i}$ & $\mathbf{P b}$ & $\mathbf{C d}$ & $\mathbf{S n}$ & Mn & Total \\
\hline Mediana (mg/L) & 148 & 47 & 43 & 0,035 & 13 & 15 & 0 & 3 & 0,05 & 531,50 \\
Max (mg/L) & 362 & 97 & 103 & 0,047 & 37 & 21 & 9 & 5 & 0,16 & \\
Min (mg/L) & 99 & 27 & 22 & 0,023 & 10 & 8 & 0 & 1 & 0,02 & \\
Porcentagem (\%) & $24,161 \%$ & $6,829 \%$ & $7,356 \%$ & $0,005 \%$ & $2,390 \%$ & $2,271 \%$ & $0,473 \%$ & $0,527 \%$ & $0,009 \%$ & $95,157^{\mathrm{a}}$ \\
\hline
\end{tabular}

Leia-se:

\begin{tabular}{ccccccccccc}
\hline Solo & $\mathbf{C r}$ & $\mathbf{Z n}$ & $\mathbf{C u}$ & $\mathbf{H g}$ & $\mathbf{N i}$ & $\mathbf{P b}$ & $\mathbf{C d}$ & $\mathbf{S n}$ & Mn & Total \\
\hline Mediana (mg/kg) & 148 & 47 & 43 & 0,035 & 13 & 15 & 0 & 3 & 0,05 & 531,50 \\
Max (mg/kg) & 362 & 97 & 103 & 0,047 & 37 & 21 & 9 & 5 & 0,16 & \\
Min (mg/kg) & 99 & 27 & 22 & 0,023 & 10 & 8 & 0 & 1 & 0,02 & \\
Porcentagem (\%) & $24,161 \%$ & $6,829 \%$ & $7,356 \%$ & $0,005 \%$ & $2,390 \%$ & $2,271 \%$ & $0,473 \%$ & $0,527 \%$ & $0,009 \%$ & $95,157^{\mathrm{a}}$ \\
\hline
\end{tabular}

